\title{
Research on resistance features of plate heat exchanger based on flow distribution
}

\author{
Sun Yong, Rong Jiayu, Tian Yanan, Niu Yanxu, Zhang Menghao \\ College of Energy and Environmental Engineering, Hebei Institute of Architecture and Civil Engineering, Zhangjiakou \\ 075000, China
}

Corresponding Author Email: zjkrong@126.com

https://doi.org/10.18280/ijht.360135

Received: 18 August 2017

Accepted: 22 December 2017

Keywords:

Plate heat exchanger, Flow distribution,

Resistance features

\begin{abstract}
This paper aims to disclose the resistance features of plate heat exchanger, a common heat transfer device and a major producer of flow resistance. For this purpose, the author examined the flow features within the plate heat exchanger, and established a resistance calculation model for the exchanger. hen, the model was solved through both numerical simulation and mathematical analysis. On this basis, an actual plate heat exchanger was simulated by the model, with the aim to acquire the exchanger resistance and the flow distribution across different paths. The results show that the deviation between the calculation results and the test results was $5.8 \%$; the path flow decreased with the increase in the distance between the path and the inlet; the decline was steep at the beginning, and disappeared at the path sufficiently far away from the inlet. In summary, this research identifies the resistance of plate heat exchanger, and obtains the flow distribution of each path in the exchanger. Suffice it to say that the research findings provide new insights into the resistance calculation of plate heat exchangers in actual engineering.
\end{abstract}

\section{INTRODUCTION}

With a good heat exchange effect and compact structure, the plate heat exchanger has been extensively applied in heating engineering. Over the years, many scholars have investigated the resistance of the plate heat exchanger, because it is the major source of flow resistance in the heating system.

For example, Focke [1] conducted an experiment on the immensely popular herringbone plate heat exchanger, and clarified the correlation between corrugation angle and resistance performance, laying the basis for the theoretical flow research of corrugated plate heat exchanger. Xu Zhiming of Northeast Electric Power University [2] created a liquid-to-liquid plate heat exchanger testbed, and a universal correlation function between the friction factor and the Nusselt number. His research sheds new light on the design and calculation of plate heat exchanger. Qu Ning of Shandong University [3] fitted the integrated criterion relation through a numerical simulation of herringbone plate heat exchanger. Based on the existing experimental data, Zhao Zhennan of Tianjin University [4] disclosed the effects of the basic flow pattern of herringbone corrugation and corrugation angle on the performance of plate heat exchanger, and proved through analytical calculation and test that smallangle and large-angle plates have basically the same film coefficient of heat transfer under the same resistance drop.

In general, the existing research on the resistance of plate heat exchanger concentrates on a single configuration of corrugated plate, and attempts to obtain the local resistance coefficient of the specific type of plate. However, an actual plate heat exchanger may contain tens to hundreds of plates. It is extremely difficult, if not impossible, to derive the total resistance of the exchanger solely based on local resistance coefficients [5-7].

To solve the problem, this paper aims to capture the flow features in the plate heat exchanger, find the way to calculate the total flow resistance of the exchanger, and obtain the flow distribution across different paths in the exchanger. For these purposes, the author established a resistance calculation model for plate heat exchanger, and determined the proper method to solve the it. Then, the proposed model was applied to deduce the total resistance and path flow distribution of an actual plate heat exchanger. Finally, the calculation results were contrasted with the measured results to verify the performance of the model.

\section{MODEL ESTABLISHMENT AND SOLUTION}

There are two flows in plate heat exchanger: the hot side flow and the cold side flow. From the hot side, the water enters the exchanger from a lower corner hole, and splits into several paths through the lower main pipe, which consists of numerous corner holes; then, the water from different paths converges into the upper main pipe, which also contains numerous corner holes, and leaves the exchanger through an upper corner hole. The cold side flow is exactly the opposite to the hot side flow. The cold-water paths and hot-water paths are arranged alternatively in the exchanger [8-14].

The cold side flow was selected as the research object. As shown in Figure 1, the cold water enters in the exchanger from the upper left corner hole, exchanges heat in oddnumbered paths, and leaves the exchanger through the lower left corner hole. Since the upper and lower corner holes are on the same side, all cold-water paths are in the shape of a U. 
Besides, the cold-water paths are parallel to each other, because the water in each path starts from the inlet of the first path and ends at the outlet of the first path. Therefore, the total resistance of the exchanger equals the resistance of the U-shape flow in any path.

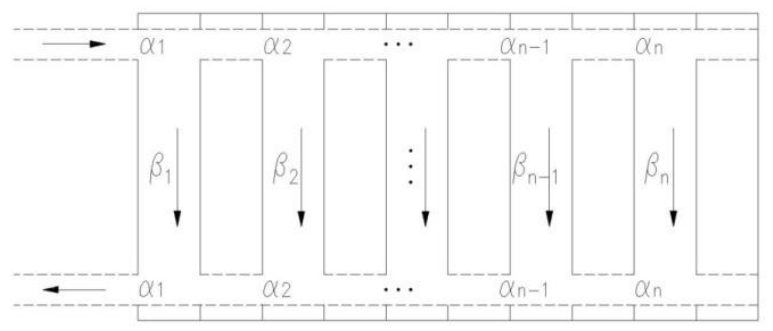

Figure 1. Cold side flow pattern of the plate heat exchanger

Let $\alpha_{1}$ and $\beta_{1}$ be the resistance at the corner hole (corner hole resistance) and the resistance at the plate (plate resistance) of the first path, respectively; Let $\alpha_{2}$ and $\beta_{2}$ be the corner hole resistance and plate resistance of the second path, respectively. The corner hole and plate resistances of other paths were defined in the same manner. Then, the following equations can be derived.

$\left\{\begin{array}{c}\beta_{1}=2 \alpha_{1}+\beta_{2} \\ \beta_{2}=2 \alpha_{2}+\beta_{3} \\ \cdots \cdots \\ \beta_{n-1}=2 \alpha_{n}+\beta_{n}\end{array}\right.$

where $\Delta P$ is the total resistance of the exchanger $\left(\mathrm{mH}_{2} \mathrm{O}\right) ; \alpha_{n}$ is the corner hole resistance of the $n$-th path $\left(\mathrm{mH}_{2} \mathrm{O}\right) ; \beta_{n}$ is the plate resistance of the $\mathrm{n}$-th path $\left(\mathrm{mH}_{2} \mathrm{O}\right)$.

Thus, the total resistance of the exchanger can be expressed as:

$\Delta P=2 \alpha_{1}+\beta_{1}$

According to the local resistance equation in fluid mechanics, we have:

$\Delta P=\xi \frac{V^{2}}{2 \mathrm{~g}}$

Thus, $\alpha_{\mathrm{n}}$ and $\beta_{\mathrm{n}}$ can be expressed as follows:

$\alpha_{n}=\xi_{1} \frac{V_{j n}{ }^{2}}{2 g}$

$\beta_{n}=\xi_{2} \frac{V_{n}^{2}}{2 g}$

where $V_{j n}$ is the flow at the corner hole $(\mathrm{m} / \mathrm{s}) ; V_{n}$ is the flow in the path $(\mathrm{m} / \mathrm{s}) ; \xi_{1}$ is the local resistance coefficient at the corner hole; $\xi_{2}$ is the local resistance coefficient at the plate; $g$ is the gravitational acceleration $(9.8 \mathrm{~m} / \mathrm{s})$.

The equation for the total resistance of the exchanger can be derived from equations (2), (4) and (5):
$\Delta P=2 \xi_{1} \frac{V_{j 1}{ }^{2}}{2 g}+2 \xi_{2} \frac{V_{1}^{2}}{2 g}$

Substituting equations (4) and (5) into equation (1), we have:

$\left\{\begin{array}{c}\xi_{\frac{V_{1}}{2 g}}=2 \xi_{1} \frac{V_{j 2}{ }^{2}}{2 g}+\xi_{2} \frac{V_{2}{ }^{2}}{2 g} \\ \xi_{2} \frac{V_{2}{ }^{2}}{2 g}=2 \xi_{1} \frac{V_{j 3}{ }^{2}}{2 g}+\xi_{2} \frac{V_{3}{ }^{2}}{2 g} \\ \cdots \cdots \\ \xi_{2} \frac{V_{n-1}{ }^{2}}{2 g}=2 \xi_{1} \\ \frac{V_{j n}{ }^{2}}{2 g}+\xi_{2} \frac{V_{n}{ }^{2}}{2 g}\end{array}\right.$

Then, the flow of the main pipe can be expressed as:

$$
\left\{\begin{array}{c}
V_{j 2}=\left(V_{2}+V_{3}+\cdots+V_{n}\right) \frac{A_{d}}{A_{j}} \\
V_{j 3}=\left(V_{3}+V_{4}+\cdots+V_{n}\right) \frac{A_{d}}{A_{j}} \\
\cdots \cdots \\
V_{j n-1}=V_{n} \frac{A_{d}}{A_{j}}
\end{array}\right.
$$

where $A_{d}$ is the cross-sectional area of the path $\left(\mathrm{m}^{2}\right) ; A_{j}$ is the area of the corner hole $\left(\mathrm{m}^{2}\right)$.

Substituting equation set (8) into equation set (7), we have:

$\left\{\begin{array}{l}\xi_{2} \frac{V_{1}^{2}}{2 g}=2 \xi_{1} \frac{\left(\frac{A_{d}}{A_{j}}\right)^{2}\left(V_{2}+V_{3}+\cdots+V_{n}\right)^{2}}{2 g}+\xi_{2} \frac{V_{2}^{2}}{2 g} \\ \xi_{2} \frac{V_{2}^{2}}{2 g}=2 \xi_{1} \frac{\left(\frac{A_{d}}{A_{j}}\right)^{2}\left(V_{3}+V_{4}+\cdots+V_{n}\right)^{2}}{2 g}+\xi_{2} \frac{V_{3}^{2}}{2 g} \\ \cdots \cdots \\ \xi_{2} \frac{V_{n-1}{ }^{2}}{2 g}=2 \xi_{1} \frac{\left(\frac{A_{d}}{A_{j}}\right)^{2} V_{n}^{2}}{2 g}+\xi_{2} \frac{V_{n}^{2}}{2 g}\end{array}\right.$

Meanwhile, the following equation holds:

$G_{Z}=\mathrm{A}_{j}\left(V_{1}+V_{2}+\cdots+V_{n}\right)$

where $G_{Z}$ is the total flow of the exchanger $\left(\mathrm{m}^{3} / \mathrm{h}\right)$.

With $\mathrm{n}$ equations and $\mathrm{n}$ unknown numbers, equations (9) and (10) form a n-variate quadratic equation set. The flow in each path $V_{l} \ldots V_{n}$ can be obtained by solving the equation set. The total resistance of the exchanger can be derived by substituting the flow in the first path $V_{l}$ into equation (6). Moreover, equations (6), (9) and (10) constitute the resistance calculation model of the exchanger. In other words, the resistance of the exchanger can be calculated by solving the set of these equations.

\section{SOLUTION AND APPLICATION OF RESISTANCE CALCULATION MODEL}

\subsection{Model solution}

As shown in Figure 2, the resistance calculation model was solved through the following steps: 
(1) The unknown parameters were solved. Specifically, the cross-sectional area of the path $A_{d}$, the area of the corner hole $A_{j}$, and the local resistance coefficient of the plate $\xi_{2}$ were extracted from vendor data; the local resistance coefficient at the corner hole $\xi_{1}$ was obtained through numerical simulation.

(2) The obtained parameters were substituted into equations (9) and (10), forming the corresponding equation set. The equation set was then solved in mathematical analysis software to obtain the flow rate in each path $V_{l} \ldots V_{n}$.

(3) The flow rate in the first path $V_{l}$ and the other parameters were substituted into equation (6) to produce the total resistance of plate heat exchanger, marking the end of model solution.

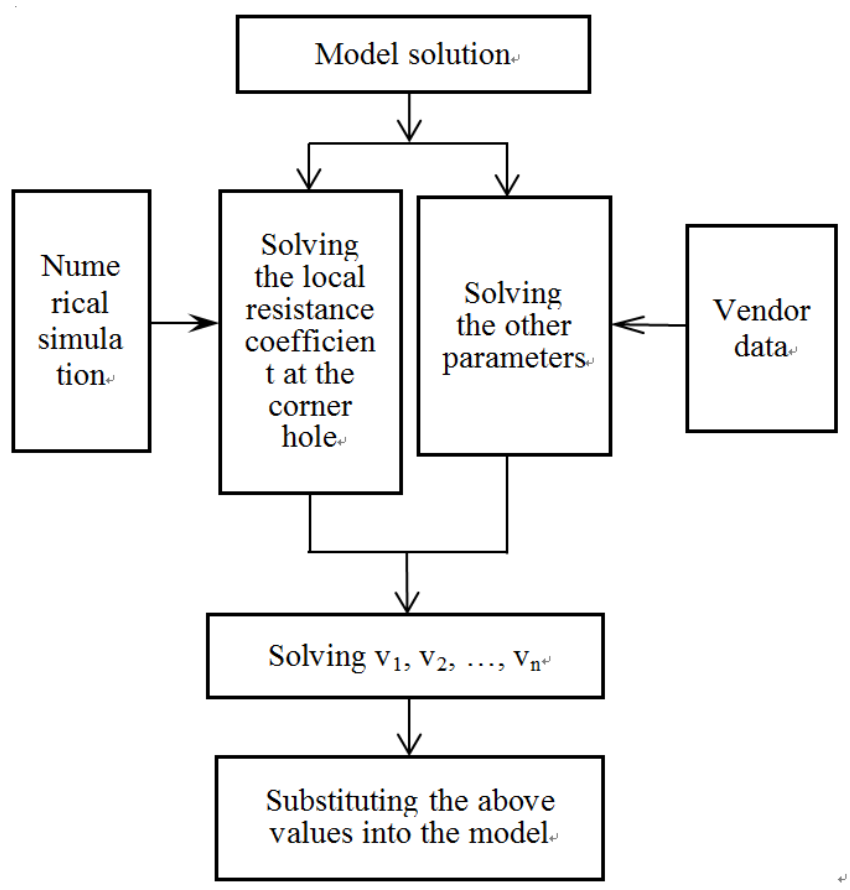

Figure 2. Flow chart of model solution

\subsection{Model application}

For verification, the proposed model was applied to simulate an actual plate heat exchanger in a heat station, and the calculation results were compared with the test results.

The parameters of the exchanger are listed in Table 1, and the parameters of the BR0.7 plate in the exchanger are presented in Table 2 .

(1) Solving the local resistance coefficient at corner hole Taking the BR0.7 plate as the sample, the corner hole simulation covers the triangular-like area within the thick line at the inlet of the plate (Figure 3 ).

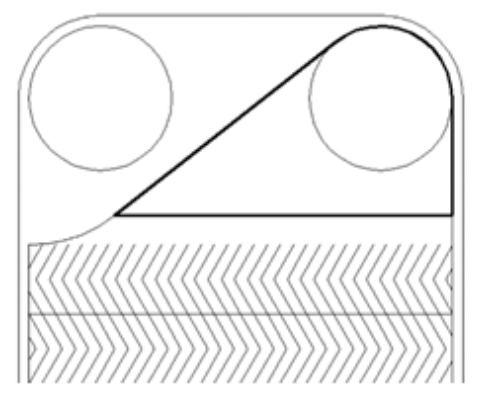

Figure 3. The simulated area of the plate
The dimensions of the simulated area are further detailed in Figure 4. In the front view, the inlet is $160 \mathrm{~mm}$ in diameter, $210 \mathrm{~mm}$ in height and $378 \mathrm{~mm}$ in width; in the left view and the top view, the wide part is the inlet main pipe $(8.8 \mathrm{~mm}$ wide), while the narrow part is the path between two plates (4.4mm-wide).

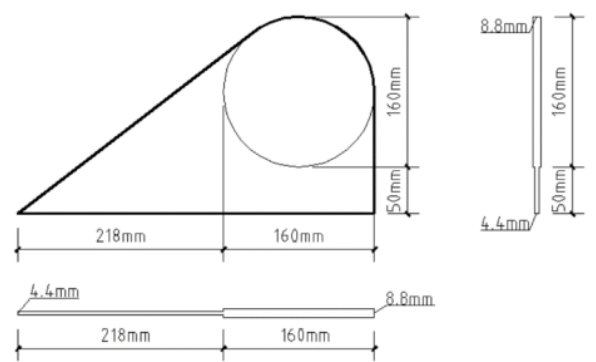

Figure 4. The diameters of the simulated area

Then, the simulated area was meshed into about 620,000 structured hexahedral grids in the ANSYS ICEM CFD meshing tool. For better convergence, a total of 5 paths were simulated, and buffer zones were added to the inlet and outlet of the main pipe. This is because the simulation equation cannot converge if only one path is simulated, as the horizontal dimension is way smaller than the vertical dimension. The final grids are given in Figures 5, 6 and 7 .

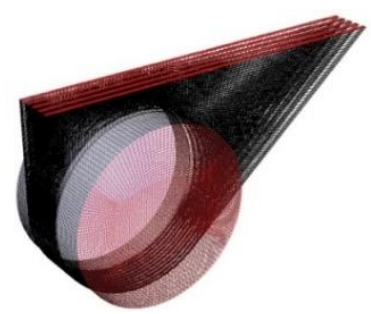

Figure 5. Oblique view of a part of the simulated area

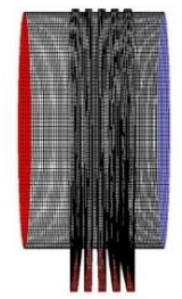

Figure 6. Side view of a part of the simulated area

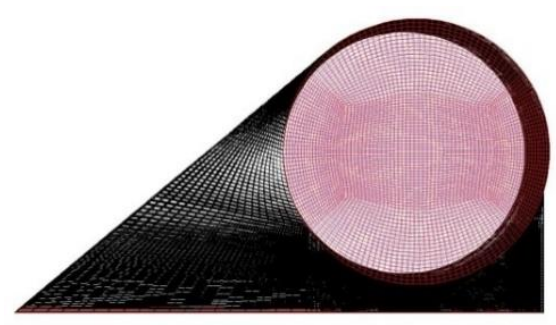

Figure 7. Front view of a part of the simulated area

The simulation uses 3D single-precision calculation and the standard k-epsilon turbulence model. The gravity was neglected. Based on the pressure solver, the velocity inlet 
boundary conditions were applied to the inlet (inlet flow: $2 \mathrm{~m} / \mathrm{s}$ ), while the pressure outlet boundary condition were applied to the outlet. The water was assumed to enter the exchanger from the left side (Figure 6) and exit from the lower right side. The simulation results are illustrated in Figure 8 .
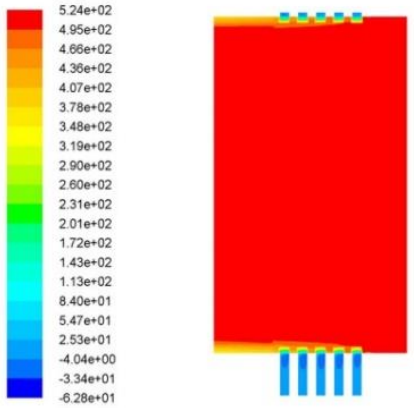

Figure 8. Simulation results

As shown in Figure 8, the pressure difference between the left inlet and the lower outlet of the main pipe was $528 \mathrm{~Pa}$ or $0.0528\left(\mathrm{mH}_{2} \mathrm{O}\right)$. Substituting the pressure difference into the local resistance equation, we have:

$\Delta P_{1}=\xi_{1} \frac{V^{2}}{2 \mathrm{~g}}=0.0528 \mathrm{mH}_{2} O$

where $\Delta P_{1}$ is the corner hole resistance $\left(\mathrm{mH}_{2} \mathrm{O}\right) ; \xi_{1}$ is the local resistance coefficient at the corner hole; $V$ is the flow rate in the main pipe $(2 \mathrm{~m} / \mathrm{s}) ; g$ is the gravitational acceleration $(9.8 \mathrm{~m} / \mathrm{s})$.
Thus, local resistance coefficient at the corner hole can be obtained as: $\xi_{1}=0.264$.

(2) Solving the resistance of the exchanger

The value of $\xi_{1}$ was substituted into equations (9) and (10) to obtain the corresponding 50-variate quadratic equation set:

$$
\left\{\begin{array}{c}
230 \cdot \frac{V_{1}^{2}}{19.6}=2 \cdot 0.264 \cdot \frac{\left(\frac{0.002035}{0.07065}\right)^{2}\left(V_{2}+V_{3}+\cdots+V_{50}\right)^{2}}{19.6}+230 \cdot \frac{V_{2}^{2}}{19.6} \\
230 \cdot \frac{V_{2}^{2}}{19.6}=2 \cdot 0.264 \cdot \frac{\left(\frac{0.002035}{0.07065}\right)^{2}\left(V_{3}+V_{4}+\cdots+V_{50}\right)^{2}}{19.6}+230 \cdot \frac{V_{3}^{2}}{19.6} \\
\ldots \ldots \\
230 \cdot \frac{V_{n-1}^{2}}{19.6}=2 \cdot 0.264 \cdot \frac{\left(\frac{0.002035}{0.07065}\right)^{2}\left(V_{50}\right)^{2}}{19.6}+230 \cdot \frac{V_{n}^{2}}{19.6} \\
\frac{10}{3600}=0.020096\left(V_{1}+V_{2}+\cdots+V_{50}\right)
\end{array}\right.
$$

The equation set can be simplified as:

$$
\left\{\begin{array}{c}
V_{1}^{2}-V_{2}^{2}=0.0000233\left(V_{2}+V_{3}+\cdots+V_{50}\right)^{2} \\
V_{2}{ }^{2}-V_{3}^{2}=0.0000233\left(V_{3}+V_{4}+\cdots+V_{50}\right)^{2} \\
\cdots \cdots \\
V_{49}{ }^{2}-V_{50}{ }^{2}=0.0000233\left(V_{50}\right)^{2} \\
V_{1}+V_{2}+\cdots+V_{50}=27.3
\end{array}\right.
$$

Table 1. Parameters of an actual plate heat exchanger in a heat station

\begin{tabular}{ccccccc}
\hline Name & Model & $\begin{array}{c}\text { Number of } \\
\text { plates }\end{array}$ & Flow $\left(\mathrm{m}^{3} / \mathrm{h}\right)$ & $\begin{array}{c}\text { Cold side inlet } \\
\text { pressure (MPa) }\end{array}$ & $\begin{array}{c}\text { Cold side outlet } \\
\text { pressure (MPa) }\end{array}$ & $\begin{array}{c}\text { Cold side pressure } \\
\text { difference }(\mathrm{MPa})\end{array}$ \\
\hline Plate heat exchanger & BR0.7 & 100 & 202 & 0.584 & 0.525 & 0.059 \\
\hline
\end{tabular}

Table 2. Parameters of the BR0.7 plate

\begin{tabular}{ccccccc}
\hline Name & Model & Plate area $\left(\mathrm{m}^{2}\right)$ & $\begin{array}{c}\text { Cross-sectional area } \\
\text { of a single path }\left(\mathrm{m}^{2}\right)\end{array}$ & $\begin{array}{c}\text { Corner hole } \\
\text { diameter }\end{array}$ & $\begin{array}{c}\text { Cross-sectional area } \\
\text { of corner hole }\left(\mathrm{m}^{2}\right)\end{array}$ & $\begin{array}{c}\text { Local resistance } \\
\text { coefficient of plate }\end{array}$ \\
\hline Plate & BR0.7 & 0.71 & 0.002035 & DN150 & 0.020096 & 230 \\
\hline
\end{tabular}

Table 3. The flow rate of each path in the exchanger

\begin{tabular}{ccccccccccc}
\hline Channel No. & $\begin{array}{c}\text { Flow rate } \\
(\mathrm{m} / \mathrm{s})\end{array}$ & Channel No. & $\begin{array}{c}\text { Flow rate } \\
(\mathrm{m} / \mathrm{s})\end{array}$ & Channel No. & $\begin{array}{c}\text { Flow rate } \\
(\mathrm{m} / \mathrm{s})\end{array}$ & $\begin{array}{c}\text { Channel No. } \\
\text { Flow rate } \\
(\mathrm{m} / \mathrm{s})\end{array}$ & $\begin{array}{c}\text { Channel No. } \\
(\mathrm{m} / \mathrm{s})\end{array}$ \\
\hline $\mathrm{V}_{1}$ & 0.672 & $\mathrm{~V}_{11}$ & 0.570 & $\mathrm{~V}_{21}$ & 0.538 & $\mathrm{~V}_{31}$ & 0.521 & $\mathrm{~V}_{41}$ & 0.508 \\
\hline $\mathrm{V}_{2}$ & 0.660 & $\mathrm{~V}_{12}$ & 0.566 & $\mathrm{~V}_{22}$ & 0.539 & $\mathrm{~V}_{32}$ & 0.519 & $\mathrm{~V}_{42}$ & 0.508 \\
\hline $\mathrm{V}_{3}$ & 0.648 & $\mathrm{~V}_{13}$ & 0.565 & $\mathrm{~V}_{23}$ & 0.537 & $\mathrm{~V}_{33}$ & 0.517 & $\mathrm{~V}_{43}$ & 0.508 \\
\hline $\mathrm{V}_{4}$ & 0.636 & $\mathrm{~V}_{14}$ & 0.557 & $\mathrm{~V}_{24}$ & 0.538 & $\mathrm{~V}_{34}$ & 0.516 & $\mathrm{~V}_{44}$ & 0.507 \\
\hline $\mathrm{V}_{5}$ & 0.625 & $\mathrm{~V}_{15}$ & 0.554 & $\mathrm{~V}_{25}$ & 0.539 & $\mathrm{~V}_{35}$ & 0.514 & $\mathrm{~V}_{45}$ & 0.507 \\
\hline $\mathrm{V}_{6}$ & 0.614 & $\mathrm{~V}_{16}$ & 0.552 & $\mathrm{~V}_{26}$ & 0.531 & $\mathrm{~V}_{36}$ & 0.513 & $\mathrm{~V}_{46}$ & 0.507 \\
\hline $\mathrm{V}_{7}$ & 0.603 & $\mathrm{~V}_{17}$ & 0.547 & $\mathrm{~V}_{27}$ & 0.532 & $\mathrm{~V}_{37}$ & 0.512 & $\mathrm{~V}_{47}$ & 0.507 \\
\hline $\mathrm{V}_{8}$ & 0.593 & $\mathrm{~V}_{18}$ & 0.550 & $\mathrm{~V}_{28}$ & 0.529 & $\mathrm{~V}_{38}$ & 0.511 & $\mathrm{~V}_{48}$ & 0.507 \\
\hline $\mathrm{V}_{9}$ & 0.584 & $\mathrm{~V}_{19}$ & 0.544 & $\mathrm{~V}_{29}$ & 0.526 & $\mathrm{~V}_{39}$ & 0.510 & $\mathrm{~V}_{49}$ & 0.507 \\
\hline $\mathrm{V}_{10}$ & 0.579 & $\mathrm{~V}_{20}$ & 0.543 & $\mathrm{~V}_{30}$ & 0.524 & $\mathrm{~V}_{40}$ & 0.509 & $\mathrm{~V}_{50}$ & 0.507 \\
\hline
\end{tabular}

Next, the equation set was coded and inputted to mathematical analysis software, and converged to $10^{-50}$ by the Levenberg-Marquardt algorithm. The maximum number of iterations was set to 2,000. The entire computation lasted 
6h. Table 3 records the flow rate of each path in the exchanger.

Table 3 shows that the first path had the fastest flow rate $(0.672 \mathrm{~m} / \mathrm{s})$ in the exchanger, while the last path had the slowest flow rate $(0.507 \mathrm{~m} / \mathrm{s})$.

The total resistance of the exchanger can be obtained by substituting the parameters in the model to equation (8):

$\Delta P=2 \xi_{1} \frac{V_{j 1}{ }^{2}}{2 g}+2 \xi_{2} \frac{V_{1}^{2}}{2 g}=2 \cdot 0.264 \cdot \frac{3.15^{2}}{2 \cdot 9.8}+230 \cdot \frac{0.672^{2}}{2 \cdot 9.8}=5.56 \mathrm{mH}_{2} O$

In the actual test, the total resistance of the exchanger was measured as $0.059 \mathrm{MPa}\left(5.9 \mathrm{mH}_{2} \mathrm{O}\right), 5.8 \%$ higher than the result of our model $\left(5.56 \mathrm{mH}_{2} \mathrm{O}\right)$. The small deviation proves the rationality and reliability of the proposed calculation model.

\section{ANALYSIS OF FLOW DISTRIBUTION FEATURES}

The analysis of the flow features in the exchanger shows that the flow in each path encounters the same resistance between the inlet and the outlet of the exchanger. If the path is far away from the inlet/outlet of the exchanger, the water has to flow by many corner holes to/from the path. This process is so energy-consuming that the amount of usable energy at the plate in the path is extremely small. According to the local resistance equation, such a path has a small water flow and flow rate, and the flow is negatively correlated with the distance between the path and the inlet/outlet. The conclusions are demonstrated by the results in Table 3 .

Figure 9 depicts the relationship between the water flow and the number of paths. It is observed that the flow decreased rapidly in the first 10 paths; then, the decrease gradually slowed down in the subsequent paths, and converged to zero in the paths beyond the $30^{\text {th }}$ path.

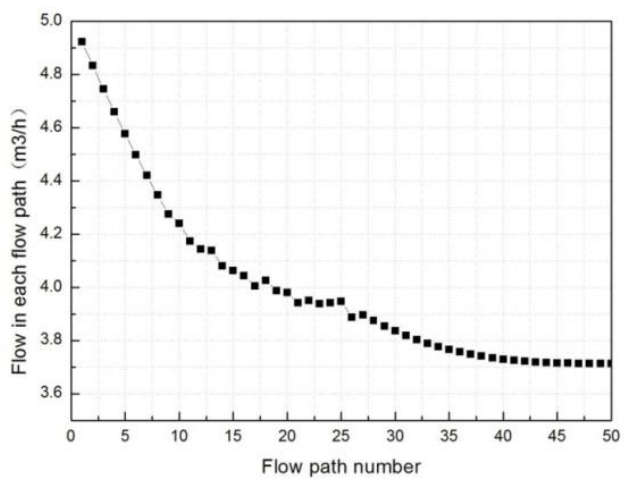

Figure 9. Flow-path number curve

\section{CONCLUSION}

Based on flow features in plate heat exchanger, this paper analyses the flow distribution in each path, and puts forward the resistance calculation model for the exchanger. Then, the model was solved and applied to calculate the resistance of an actual plate heat exchanger. The main conclusions are as follows:

(1) Since all water paths are in the shape of a $U$ in plate heat exchanger, the total resistance of the exchanger equals the resistance incurred during the U-shaped flow in any path.
Thus, the total resistance can be expressed as the sum of the resistances at the two corner holes and the plate of the first path.

(2) The deviation between the calculation results and the test results was merely $5.8 \%$, an evidence of the rationality and reliability of the proposed model.

(3) The flow differs from path to path due to the resistance at the corner hole. The path flow decreased with the increase in the distance between the path and the inlet; the decline was steep at the beginning, and disappeared at the path sufficiently far away from the inlet.

\section{REFERENCES}

[1] Focke WW, Zacharlades J, Olivier I. (1985). The effect of the corrugation incImation angle Oil the thermohydraulic performance of plate heat exchangers. International Journal of Heat and Mass Transfer 28(8): 1469-1479.

[2] Xu ZM, Guo JS, Guo JS, Huang X, Zhang ZB. (2010). Experimental study on pressure drop and heat transfer characteristics of plate heat exchanger. Journal of Thermal Science and Technology 9(1). https://doi.org/ 10.3969/j.issn.1671-8097.2010.01.003

[3] Qu N. (2005). Heat transfer and flow analysis of plate heat exchanger. Shandong University. https://doi.org/ 10.7666/d.y971432

[4] Zhao ZN. (2001). Effects of the corrugated inclination angle on heat transfer and resistance performances of plate heat exchangers. Petro-Chemical Equipment. https://doi.org/10.3969/j.issn.1000-7466.2001.z1.001

[5] Guo CS. (2012). Theoretical analysis and experimental study on heat transfer and flow of a new type of composite herringbone plate heat exchanger. Shandong University, Jinan, Shandong, China. https://doi.org/ 10.7666/d.y2185160

[6] Tsai YC, Liu FBT, Shen PT. (2009). Investigations of the pressRte drop and flow distrution in a chevrontype plate heat exchanger. International Communications in Heat and Mass Transfer 36(6): 574578.

[7] Gherasim I, Galanis N, Nguyen CT. (2011). Heat transfer and fluid flow in a plate heat exchanger. Part II:Assessment of laminar and two-equation turbulent modeb. International Journal of Thermal Sciences 50(8): 1499-1511.

[8] Kanaris AG, Mouza A, Paras SV. (2009). Optal design of a plate heat exchanger with undulated surfaces. International Journal of Thermal Sciences 48: 11841195.

[9] Wang W, Zhang S., Yang J., Ding X., Chou M., Tang P., Zhan X.. (2013). Effects of distribution channel dimensions on flow distribution and pressure drop in a plate-fin heat exchanger. Chemical Engineering and Technology 36(4): 657-664. http://dx.doi.org/ 10.1002/ceat.201200584

[10] Kumar, Bhupal, Singh, S.N.. (2017). Study of pressure drop in single pass U-type plate heat exchanger. Experimental Thermal and Fluid Science 87: 40-49. http://dx.doi.org/ 10.1016/j.expthermflusci.2017.04.028

[11] Khan Tariq S., Khan Mohammad S., Ayub Zahid H. (2017). Single-phase flow pressure drop analysis in a plate heat exchanger. Heat Transfer Engineering 38(2): 
256-264.http://dx.doi.org/

$10.1080 / 01457632.2016 .1177430$

[12] Zhang JZ, Tian MC, Zhang GM, Li W, Ma LX, Leng XL. (2014). Heat transfer and flow resistance characteristics of plate heat exchangers with different corrugate angles. Kung Cheng $\mathrm{Je} \mathrm{Wu} \mathrm{Li}$ Hsueh Pao/Journal of Engineering Thermophysics 35(7): 1369-1373.

[13] Guo ZP, Zhou PF, Bai LL, Yang JZ, Meng YG, Du YG. (2013). Analysis and study for plate heat exchanger based on FLUENT soft. Advanced Materials Research

644:

279-283. http://dx.doi.org/10.4028/www.scientific.net /AMR.644.279

[14] Tong ZM, Yin Y, Qin GH, Tao XG, Yang QX. (2015). Study on measurement and calculation of pressure drop of mixed plate heat exchanger. Neiranji Gongcheng/Chinese Internal Combustion Engine Engineering 36(3): 72-76, 84. 